\title{
Aggregate surplus production models for demersal fishery resources of the Gulf of Maine
}

\author{
M. J. Fogarty ${ }^{1, *}$, W. J. Overholtz ${ }^{1,2}$, J. S. Link ${ }^{1}$ \\ ${ }^{1}$ Northeast Fisheries Science Center, National Marine Fisheries Service, 166 Water St., Woods Hole, Massachusetts 02543, USA \\ ${ }^{2}$ Present address: 193 Percival Rd., Falmouth, Massachusetts 02356, USA
}

\begin{abstract}
We developed surplus production models for 12 demersal fish species in the Gulf of Maine at the single-species and aggregate-species levels. Summed single-species production model reference points were higher than estimates from the aggregate surplus production model. The equilibrium yield (maximum sustainable yield, MSY) and biomass at MSY ( $B_{\mathrm{MSY}}$ ) levels for the summed single-species production model reference points exceeded the aggregate model results by 28.0 and $27.5 \%$, respectively. Biological interactions such as predation and competition are potential reasons for differences between the aggregate and summed results. Not accounting for biological interactions may result in overly optimistic predictions of long-term sustainable yield and unrealistically high estimates of $B_{\mathrm{MSY}}$. We found high concordance between single-species production model reference points and results from a range of other estimation methods employed in assessment of these species, suggesting that the results from the aggregate production model analyses are not artifacts related to model type. Tests for the effect of environmental variables, including the Atlantic Multidecadal Oscillation (AMO) index, the winter North Atlantic Oscillation (NAO) index, and the Extended Reconstructed Sea Surface Temperature (ERSST) series suggested possible effects of the NAO at a lag of 0 and the ERSST at a lag of 2 yr based on crosscorrelation analyses. However, further tests proved inconclusive when the covariates were introduced into an extended surplus production model. Given the potential shifts in productivity that can accompany climate change, this issue should be periodically re-evaluated, and, where appropriate, a more dynamic approach to setting reference points should be pursued.
\end{abstract}

KEY WORDS: Ecosystem-based fishery management $\cdot$ Reference points $\cdot$ Aggregate multispecies model $\cdot$ Environmental effects

\section{INTRODUCTION}

The Gulf of Maine is a semi-enclosed continental shelf sea delimited on its seaward boundary by Georges Bank and on its landward margins by bordering sections of the US states of Massachusetts, New Hampshire, and Maine and the Canadian provinces of New Brunswick and Nova Scotia (Fig. 1). The system is characterized by an extremely complex topography, reflecting its recent glacial history. Three major deep basins and over 20 smaller basins occur within the Gulf. Two ledge-bank systems within the Gulf, Stellwagen Bank and Jeffries Ledge, are historically important fishing grounds. Stellwagen Bank is now a designated National Marine Sanctuary. The rich mosaic of sediment types associated with these features results in high habitat diversity in the system. The deep Northeast Channel (Fig. 1) provides a major pathway for inflow of nutrient-rich continental slope water into the Gulf. These physical characteristics collectively contribute to a diverse and productive fauna. 


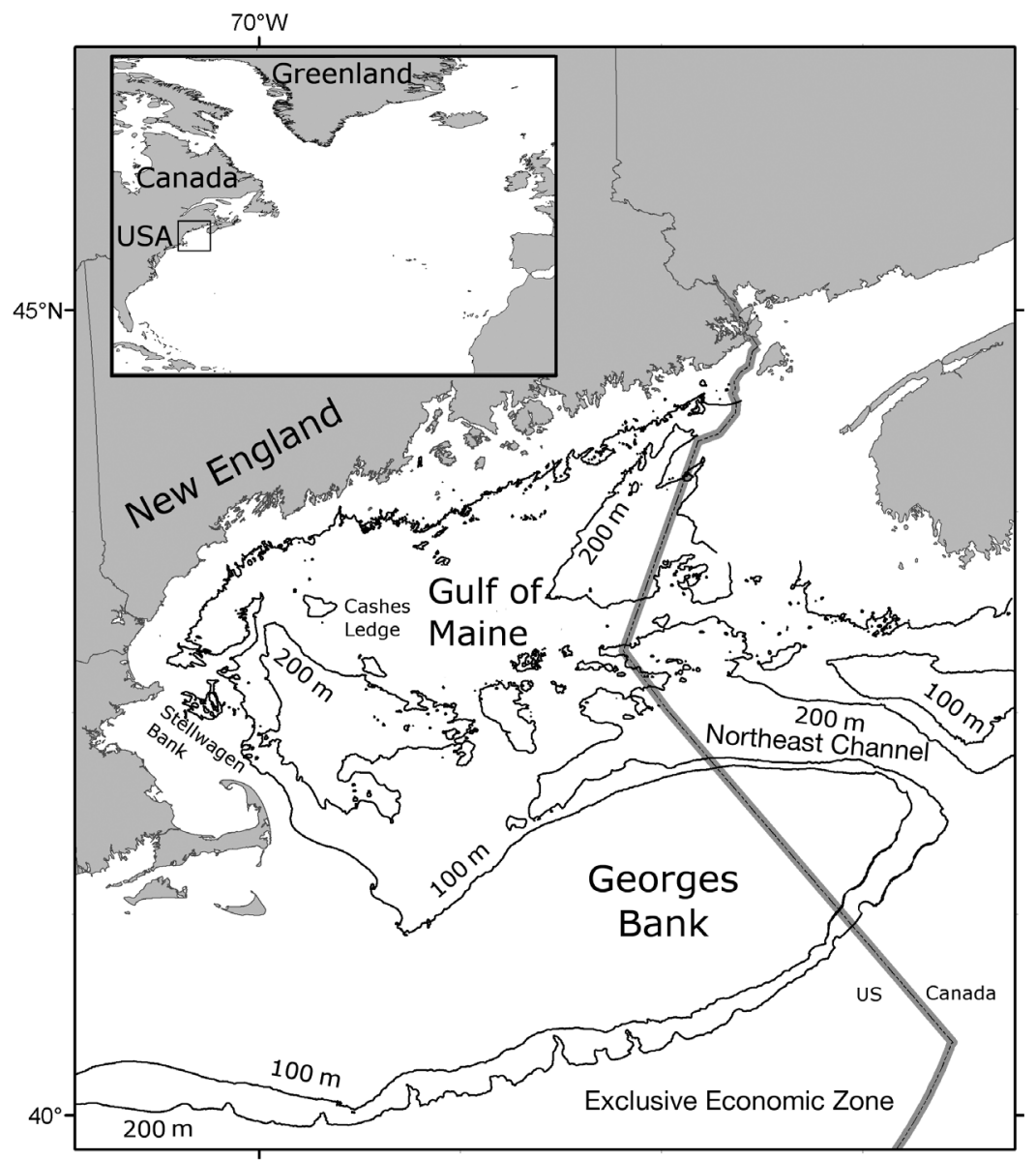

Fig. 1. Gulf of Maine, showing major basin systems, the position of the Northeast Channel, and the location of Georges Bank. The inset shows the location of the Gulf of Maine (boxed area) in the Northwest Atlantic cies in the Gulf of Maine using aggregate-species production models. These species are taken together in a mixed-species trawl fishery. Our objective was to capitalize on the greater stability and predictability of aggregate system properties using simple and robust models to estimate community-level biological reference points and to compare these results with comparable single-species model results. The aggregate-species models implicitly account for interspecific interactions among species in the assemblage. They can also readily accommodate environmental and climate forcing in an analytically tractable setting (Mueter \& Megrey 2006). Brown et al. (1976) provided one of the earliest demonstrations of the value of this general approach. For the Northeast US Continental Shelf Large Marine Ecosystem (NES LME) as a whole, an aggregate multispecies model provided more conservative biological reference points (total system maximum sustainable yield, MSY) relative to the sum of single-species MSY estimates (Brown et al. 1976). Ralston \& Polovina (1982) showed that aggregate-species production models can outperform com-
Fisheries within the Gulf, capitalizing on this productivity, were among the earliest maritime industries established following European settlement in the region over 400 yr ago (Lear 1998, Bolster 2008). For example, fisheries on Stellwagen Bank can be traced to the turn of the 17 th century (Rosenberg \& Claesson 2008), and fishing remains a major industry in the Gulf. The lobster fishery in particular is among the most valuable in the nation. The ecological structure of the Gulf of Maine has been altered radically by centuries of fishing and other human activities (Apollonio 2002). The decimation of populations of large whales, the sequential depletion of fish populations such as sturgeon (Acipenser spp.) and halibut Hippoglossus hippoglossus that have not recovered, and the impacts on diadromous species through obstruction of river systems have fundamentally changed the structure and productivity patterns in the Gulf.

We assessed the recent dynamics of an economically important assemblage of 12 demersal fish spe- parable models focused on higher levels of taxonomic resolution in the Hawaiian longline fishery. Sparholt \& Cook (2009) recently applied an aggregate production model approach to 5 Northeast Atlantic fish stocks and concluded that suitable biological reference points could be derived for this species complex in a combined-species analysis.

Tradeoffs inevitably arise in the balance of mechanistic detail and parameter uncertainty in models of multispecies systems. Aggregate production models provide one potentially effective approach to coping with the issues that emerge with increasing model complexity (Sugihara 1984). These simple models nonetheless must be carefully evaluated and the potential for adverse effects on low productivity stocks assessed (Gaichas et al. 2012). Vulnerable species (so-called weak-link stocks) will require special consideration in any management regime, and it will be particularly important to include appropriate safeguards in systems based on aggregate production dynamics. 


\section{METHODS}

Catches and abundance estimates were assembled for 12 economically important demersal fish stocks in Gulf of Maine (GOM) for the period 1964 to 2007 (Table 1). Species selected for analysis comprise dominant components of the GOM otter trawl fishery (Lucey \& Fogarty in press). Landings data were compiled for each species from the Northeast Fisheries Science Center (NEFSC) commercial fishery statistics data base. We used NEFSC autumn research survey estimates (stratified mean catch in $\mathrm{kg} \mathrm{tow}^{-1}$ ) for the GOM, adjusted for catchability to the survey gear (Brodziak et al. 2004) and the area swept by the trawl, to generate total biomass estimates (see also Link et al. 2006). Approximately 75 stations are occupied in the GOM in each survey, and the modal coefficient of the estimates for the species included in this analysis is $30 \%$. Biomass estimates for each stock were summed to produce an aggregate estimate for the 12 -species complex.

These aggregate estimates of biomass and landings were then used as primary inputs in a quadratic surplus production model. The basic approach followed the methods described by Jacobson et al. (2002) and Mueter \& Megrey (2006). We based our analysis on a discrete-time version of the simple logistic production model:

$$
B_{t+1}=B_{t}+\left(\alpha-\beta \bar{B}_{t}\right) \cdot \bar{B}_{t}-C_{t}+\varepsilon_{t}
$$

where $\alpha$ is the intrinsic rate of increase, $\beta$ is a densitydependent term, $\alpha, \beta>0, B_{t}$ is the aggregate annual biomass at time $t_{1}$ and $\varepsilon_{t}$ is a normally distributed random variable with mean 0 and constant variance. Following Mueter \& Megrey (2006), $\bar{B}_{t}=\left[B_{t+1}+B_{t}\right] / 2$. By definition, the annual surplus production in year $t$

Table 1. Demersal teleost species included in the Gulf of Maine assemblage considered in this analysis

\begin{tabular}{|ll|}
\hline Species & Common name \\
\hline Gadus morhua & Atlantic cod \\
Melanogrammus aeglefinus & Haddock \\
Merluccius bilinearis & Silver hake \\
Urophycis tenuis & White hake \\
Urophycis chuss & Red hake \\
Pollachius virens & Pollock \\
Limanda ferruginea & Yellowtail flounder \\
Pseudopleuronectes americanus & Winter flounder \\
Hippoglossoides platessoides & American plaice \\
Glyptocephalus cynoglossus & Witch flounder \\
Lophius americanus & Monkfish \\
Sebastes fasciatus & Redfish \\
\hline
\end{tabular}

$\left(\mathrm{ASP}_{t}\right)$ is the change in biomass from year $t$ to year $t+1$ plus the catch in year $t$ (e.g. Quinn \& Deriso 1999).

We can rearrange Eq. (1) to give:

$$
\mathrm{ASP}_{t}=B_{t+1}-B_{t}+C_{t}=\left(\alpha-\beta \bar{B}_{t}\right) \cdot \bar{B}_{t}+\varepsilon_{t}
$$

The MSY is given by:

$$
\mathrm{MSY}=\frac{\alpha^{2}}{4 \beta}
$$

The corresponding proportional fishing mortality at MSY is:

$$
F_{\mathrm{MSY}}=\frac{\alpha}{2}
$$

representing the annual proportion of the population removed by harvesting. Finally, the biomass level at MSY is given by:

$$
B_{\mathrm{MSY}}=\frac{\alpha}{2 \beta}
$$

The parameters $\alpha$ and $\beta$ were estimated by the method of maximum likelihood using a process-error model. We evaluated variability in the estimates of the biological reference points using a nonparametric bootstrap routine with 1000 replicates to generate probability distributions for each reference point. Because of the time series nature of the data, we employed a moving blocks bootstrap procedure (Efron \& Tibshirani 1994). The series was divided into intervals (blocks) of $3 \mathrm{yr}$, and we randomly selected a selection of these blocks rather than individual observations for each of the 1000 iterations of the bootstrap.

\section{Contrast with single-species models}

For comparison, biological reference points were also derived for each of the individual stocks using single-species production models employing the same methods used for the aggregate-species model. We then compared the summed single-species results with those for the base case aggregate model. We also compared the single-species surplus production model results with biological reference points reported in the comprehensive Groundfish Assessment Review Meeting (GARM) report (NEFSC 2008) and additional analyses for hake species. A wide range of model types was used in the GARM analyses, and the selection of reference points differed substantially from the surplus production model analysis. Models and analytical approaches for individual species in the GARM included age- and sizestructured models and index-based analyses drawing on survey (and in some cases catch) information. The GARM analyses had a principal focus on main- 
taining target levels of spawning stock biomass and specifying corresponding fishing mortality rates using spawning-biomass-per-recruit analyses. For index-based assessments, we expanded survey catch-per-tow estimates to total biomass using the area-swept and survey catchability approach described above. Once placed on an absolute scale, these reference points could then be compared with the production model results. Again, because the basis for selecting and estimating reference levels differed markedly from the production model approach, the GARM results are intended only to provide a general point of comparison and to test for concordance and directionality of overall results.

\section{Environmental effects}

We examined the potential effect of environmental or climate-related factors on surplus production in this system. The covariates used were the Atlantic Multidecadal Oscillation (AMO) index, the winter (December to February) North Atlantic Oscillation (NAO) index, and the Extended Reconstructed Sea Surface Temperature (ERSST) index for the Northeastern US. Both the NAO and AMO are basin-wide indicators. The AMO index is based on spatial patterns in SST variability after removing the effects of anthropogenic forcing on temperature (Enfield et al. 2001). The NAO is the dominant mode of climate variability over the North Atlantic Basin (Hurrell 1995) and is known to exert important ecosystem effects (Stenseth et al. 2002). The broad-scale ERSST series is based on a comprehensive analysis of long-term temperature records obtained from ships-of-opportunity (Smith \& Reynolds 2003, 2004). In each case, we converted the observations to standard normal deviates with 0 mean and unit standard deviation.

To examine candidate lags to be included in the analysis, we first examined the cross-correlation structure (Box \& Jenkins 1976) for ASP and each of the environmental covariates. Following identification of candidate environmental variables and lags, we incorporated these metrics in an extended production model:

$$
\mathrm{ASP}_{t}=\left(\alpha-\beta \bar{B}_{t}\right) \bar{B}_{t} \mathrm{e}^{\sum_{j=1}^{m} \delta_{j} X_{j, t-\tau}}+\mathrm{e}_{t}
$$

where $\delta_{\mathrm{j}}$ is a coefficient for the effect of the $j$ th covariate, $X_{j, t-\tau}$ is the value of covariate $j$ at $\operatorname{lag} \tau$, and all other terms are defined as before. All candidate models were compared using the Akaike Information Criterion (AIC; Akaike 1992) to test whether the fit with environmental covariates performed better than the base case (Eq. 2). We used the corrected $\mathrm{AIC}_{\mathrm{C}}$ to adjust for sample size effects:

$$
\mathrm{AIC}_{\mathrm{c}}=-2 \log _{\mathrm{e}}(L)+\frac{2 K(K+1)}{n-K-1}
$$

where $L$ is the likelihood estimate, $K$ is the number of parameters estimated, and $n$ is the number of observations (Burnham \& Anderson 1998).

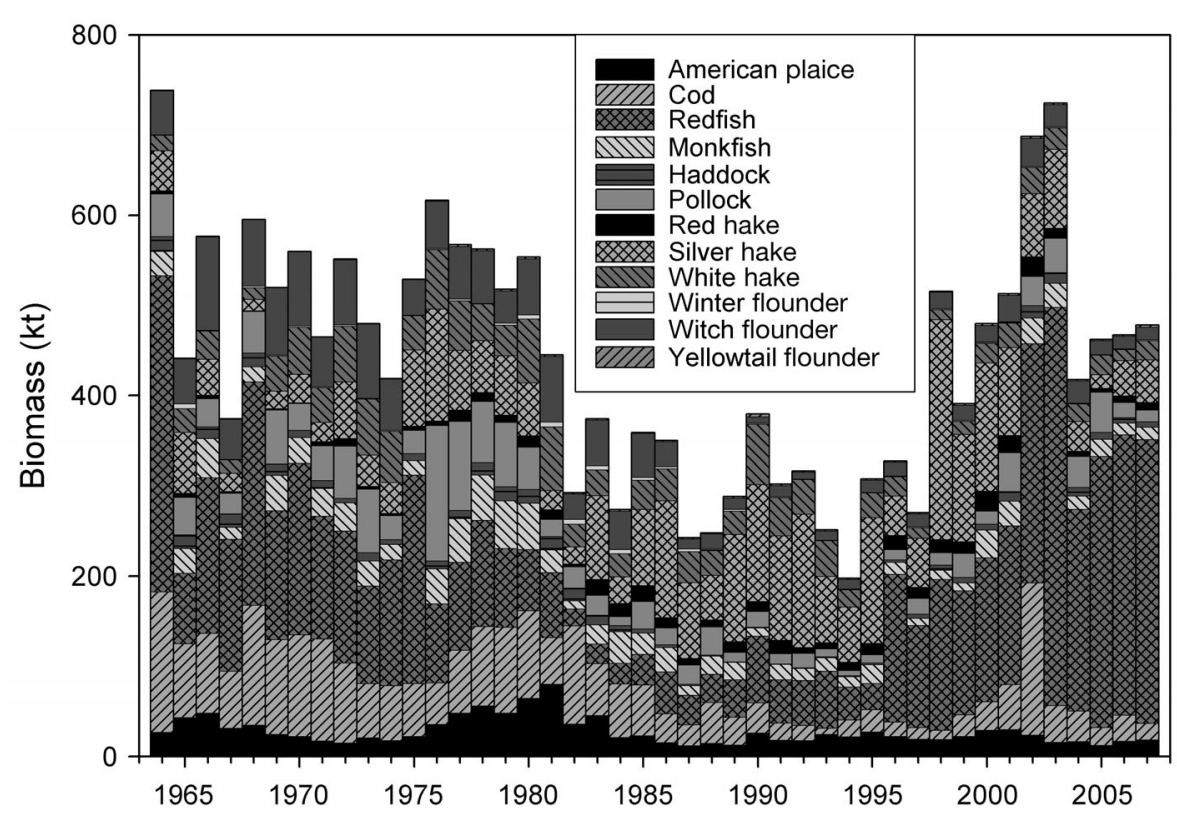

Fig. 2. Biomass (kt) of selected demersal fish species for the Gulf of Maine during 1964 to 2007

\section{RESULTS}

Aggregate biomass of the 12species complex declined through the mid-1990s but has since increased, nearly recovering to the levels at the start of the survey time series (Fig. 2). Substantial changes in relative species composition are again evident throughout the series with important changes in the abundance of key species such as cod, haddock, and redfish. The coefficient of variation of the aggregate biomass series (30.5\%) was substantially lower than that of the individual species, which ranged from 50.0 to $87.6 \%$ (mean $64.8 \%$ ). The greater relative precision of the combined series is a potential advantage of dealing with aggregate data. 
Total aggregate catch of the demersal species complex declined steadily during 1964 to 2007 . The relative species composition of the catch has varied considerably over time (Fig. 3). In particular, red hake was dominant in the first decade of the series. Sharp declines in red hake catch in this initial period accounted for the overall drop in the total catch from just under $250 \mathrm{kt}$ in 1964 to a low of $20 \mathrm{kt}$ in 2007 (Fig. 3). The coefficient of variation of the individual catch series was again higher than for the aggregate series but less markedly so than for the biomass series (mean $84.52 \%$ compared with $70.67 \%$ ) and the range of the coefficients of variation ( $\mathrm{CVs}$ ) for the individual catch series was quite broad (45.13 to $171.95 \%$ ). We note that the CV in the catch series is affected by management actions, and these have changed over the time period covered in this analysis.

The summed landings and biomass series were used to generate estimates of annual surplus production for the assemblage (Fig. 4). ASP has fluctuated in the GOM over the entire period, with several periods of negative surplus production reflecting periods of non-sustainable harvesting (Fig. 4).

\section{Contrast with single-species models}

The point estimate of the MSY for the 12-species assemblage was $74 \mathrm{kt}$ and the $B_{\mathrm{MSY}}$ was $510 \mathrm{kt}$ (Table 2). The corresponding $F_{\text {MSY }}$ was 0.16 (Table 2). Bootstrap probability distributions for each reference

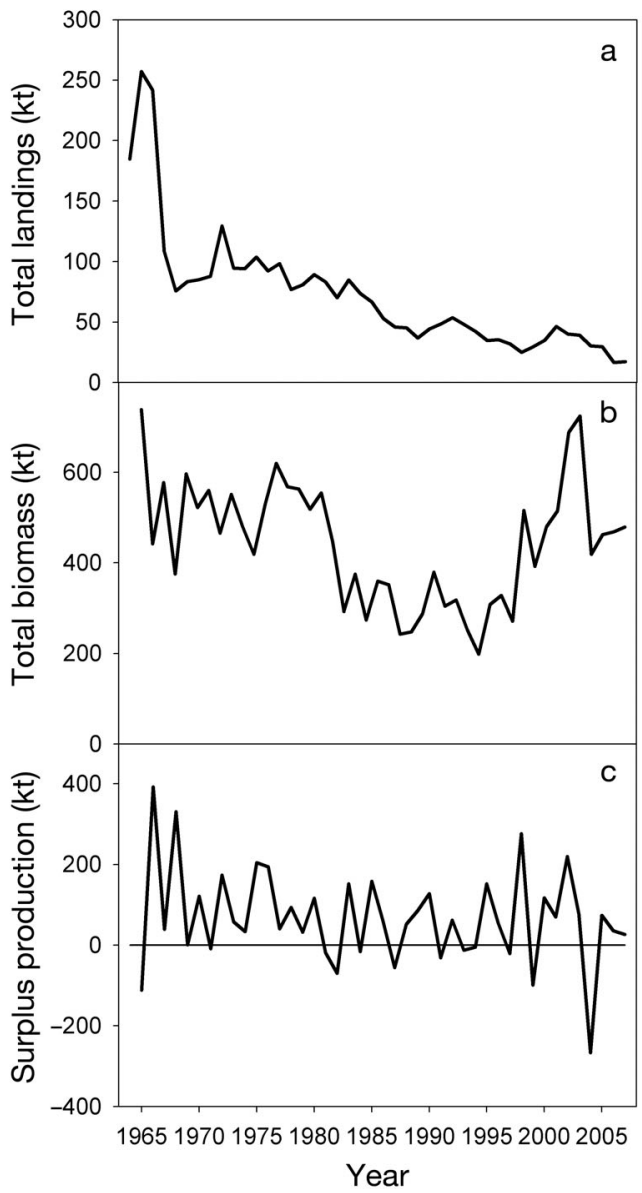

Fig. 4. (a) Total landings (kt), (b) biomass (kt), and (c) annual surplus production (kt) of 12 demersal fish species in the Gulf of Maine used in this analysis

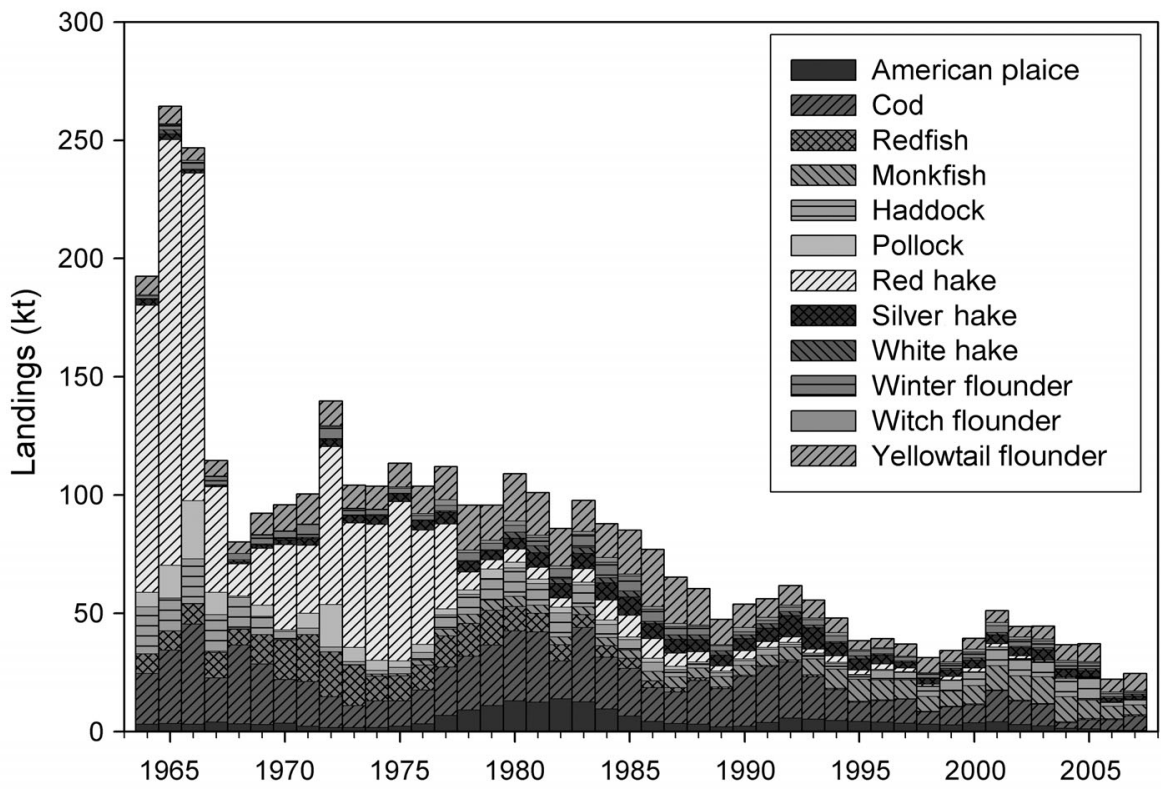

Fig. 3. Landings (kt) of selected demersal fish species for the Gulf of Maine during 1964 to 2007 point are provided in Fig. 5; the $B_{\mathrm{MSY}}$ distribution was strongly skewed with a long tail. The summed MSY estimate for the individual surplus production models (94.5 kt) was $\sim 28 \%$ higher than for the aggregate model. The summed $B_{\mathrm{MSY}}$ estimate $(650 \mathrm{kt})$ exceeded the aggregate model results by $27.5 \%$. The variability in the reference point determinations for both the aggregate and summed single-species results complicates detailed comparison and testing. Strong negative covariances between the parameter estimates for MSY and $B_{\text {MSY }}$ introduces additional uncertainty because the covariance terms themselves enter the overall variance for these reference points as negative terms 
Table 2. Biological reference points derived from simple production models and Groundfish Assessment Review Meeting (GARM) assessment results (NEFSC 2008). MSY: maximum sustainable yield, $F_{\mathrm{MSY}}$ : fishing mortality at MSY, $B_{\mathrm{MSY}}$ : biomass at MSY

\begin{tabular}{|lccc|}
\hline \multirow{2}{*}{ Species } & \multicolumn{3}{c|}{ Production model reference points } \\
& $F_{\text {MSY }}$ & MSY (kt) & $B_{\text {MSY }}(\mathrm{kt})$ \\
\hline Cod & 0.27 & 18.842 & 69.329 \\
Haddock & 0.17 & 0.862 & 5.065 \\
Silver hake & 0.45 & 31.551 & 69.886 \\
White hake & 0.13 & 5.115 & 38.905 \\
Red hake & 0.44 & 3.687 & 8.437 \\
Pollock & 0.23 & 13.987 & 58.986 \\
Yellowtail flounder & 0.60 & 1.341 & 2.216 \\
Winter flounder & 0.36 & 2.557 & 7.040 \\
American plaice & 0.06 & 3.296 & 54.986 \\
Witch flounder & 0.02 & 3.045 & 15.237 \\
Monkfish & 0.15 & 4.367 & 27.977 \\
Redfish & 0.04 & 5.830 & 154.72 \\
Sum & & 94.497 & 650.030 \\
Aggregate model & 0.16 & 73.846 & 509.746 \\
\hline
\end{tabular}

The estimated $F_{\mathrm{MSY}}$ levels for individual species ranged from 0.02 to 0.60 (Table 2), reflecting both real differences in life history characteristics and the effects of noisy data at the single-species level. The single-species estimate for yellowtail flounder at $F_{\mathrm{MSY}}=0.6$ is unreasonably high, and the estimates for silver and red hake are also very high (Table 2 ). The estimate of $F_{\text {MSY }}$ for the aggregate model case (0.16) was lower than two thirds of the estimates for individual species (Fig. 6), suggesting its general utility as a conservative reference point. However, any attempt to manage using an aggregate target $F$ strategy would need to consider that some fraction of species included in the analysis would require special consideration to ensure that they were not overexploited and driven to low biomass levels because of low productivity. The use of supplemental management measures designed to reduce fishing mortality on these vulnerable stocks through gear modifications, spatial protection, and other mechanisms would be required. We note that this issue is no more problematical for the aggregate analysis than for single-species analyses for mixed-species fisheries confronting the weak stock constraint.

A comparison of derived reference points for single species production models relative to the results from the GARM and hake analyses indicate a strong concordance in results (Fig. 7). The Spearman rank order correlation for the 12 species was 0.86 for the MSY estimates and 0.81 for $B_{\mathrm{MSY}}$. Although the basis for reference point determination differs markedly in the
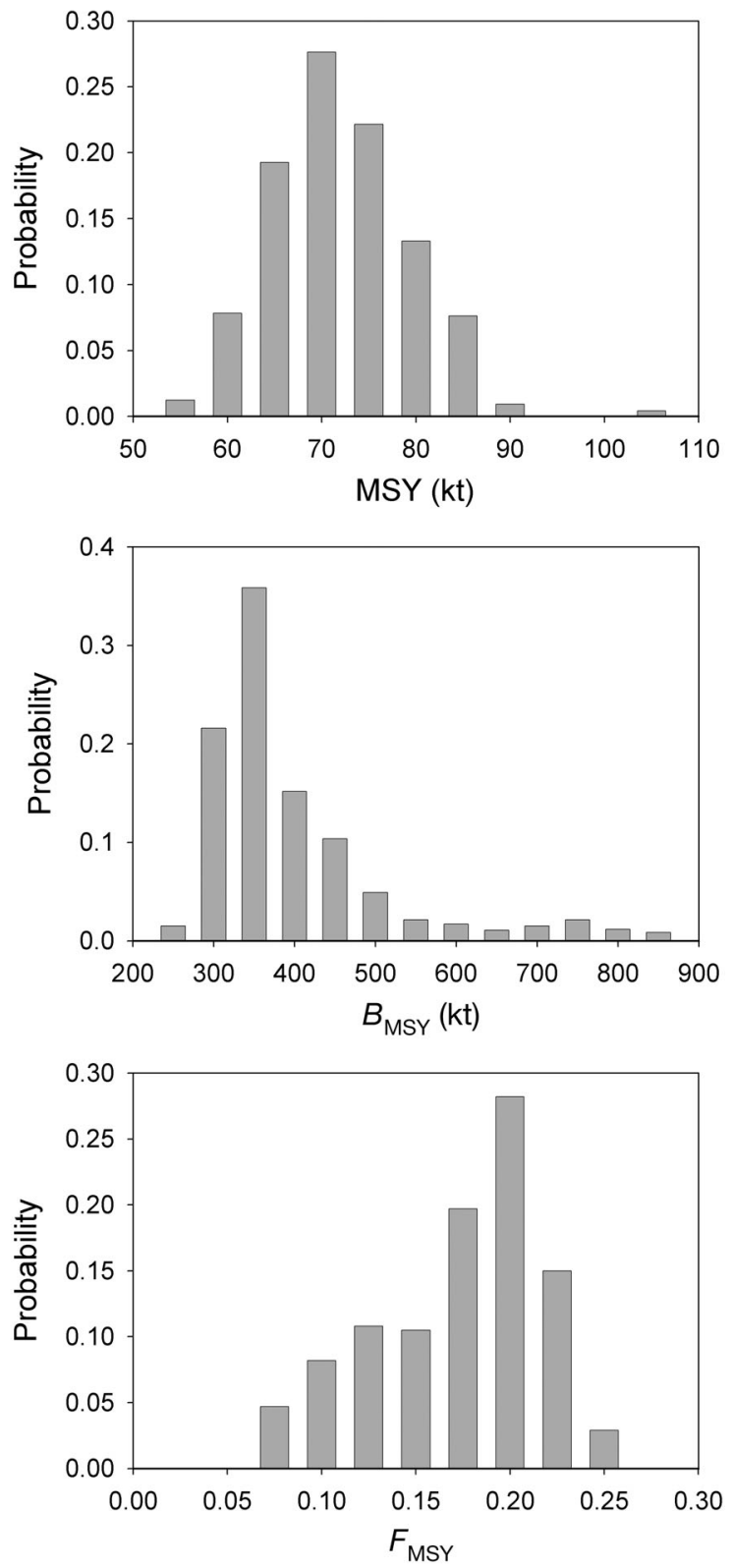

Fig. 5. Empirical probability distribution of biological reference points based on aggregate surplus production models using 1000 nonparametric bootstrap replicates for each reference point type

production model approach and the various methods employed in the GARM, the general picture that emerges is consistent for the individual species involved in both cases (Fig. 7). The greatest divergence occurs for the $B_{\mathrm{MSY}}$ estimate for redfish, which is substantially higher in the GARM analyses. The summed estimate for the 12 species is quite similar for the single-species production model and the GARM results for both MSY and $B_{\mathrm{MSY}}$ (triangles in Fig. 7). 


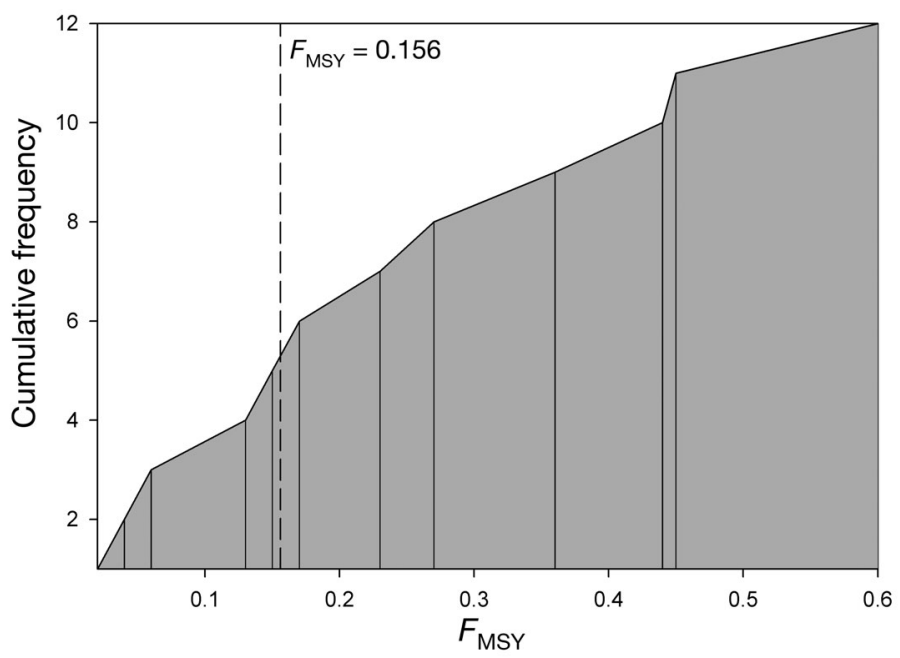

Fig. 6. Cumulative frequency distribution of fishing mortality at maximum sustainable yield $\left(F_{\mathrm{MSY}}\right)$ levels for singlespecies production model results for the 12-species system. Solid vertical lines indicate the values for individual species results. The dashed vertical line indicates the position of the aggregate species $F_{\mathrm{MSY}}$ value

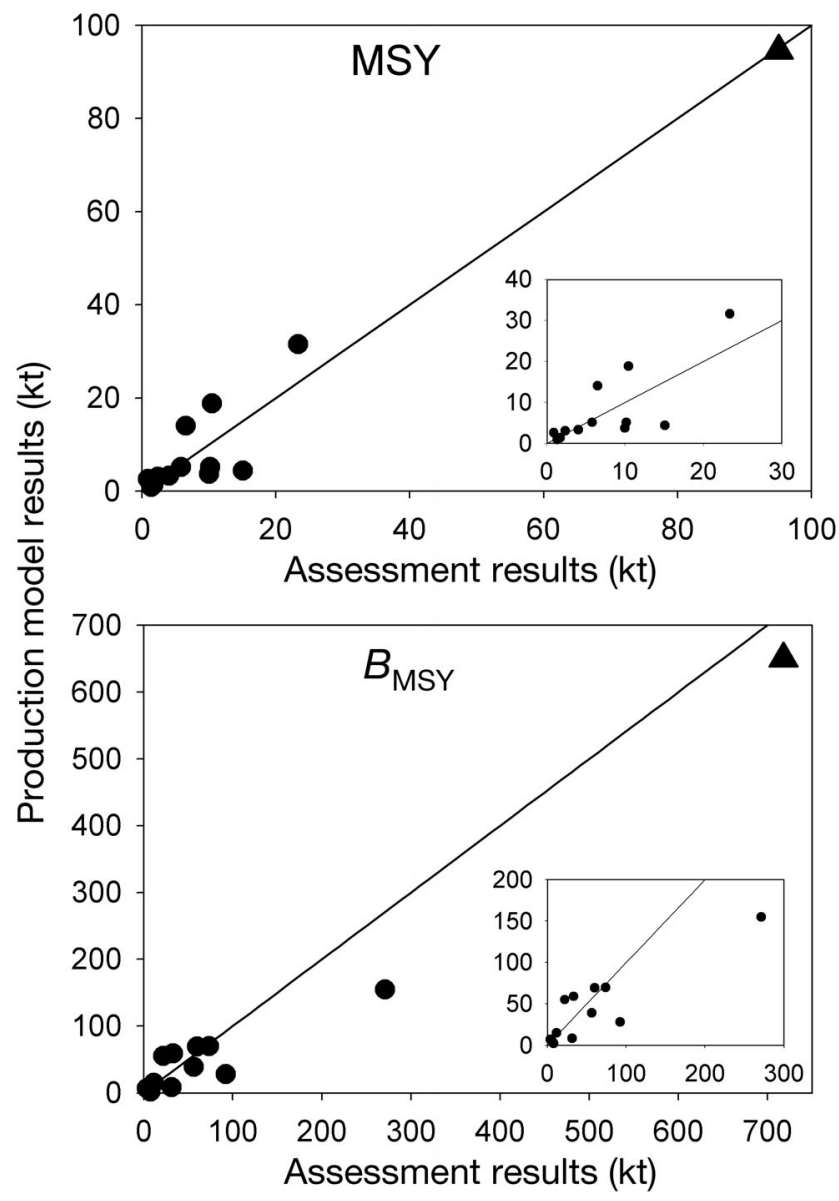

\section{Environmental effects}

The AMO index has steadily increased over the last 3 decades (Fig. 8). The first decade of the standardized NAO series was dominated by negative anomalies, followed by a preponderance of positive anomalies punctuated by some sharp reversals in the mid-1990s (Fig. 8). The ERSST series reflects generally low temperature values in the 1960s and generally high values in the last decade (Fig. 8). An examination of the cross-correlations between ASP and each of the 3 environmental variables indicated potential effects of NAO at a lag of 0 and for ERSST at a lag of 2 yr (Fig. 9). We included these terms both together and individually in extended production models to test for environmental effects. The change in $\mathrm{AIC}_{\mathrm{C}}$ scores $\left(\Delta \mathrm{AIC}_{\mathrm{c}}\right)$ was low in all cases (Table 3$)$, suggesting that further consideration of these environmental terms was not warranted at this time. Generally, a decrease in the AIC scores greater than 2 is required to be considered meaningful (Burnham \& Anderson 1998), and our results did not meet this threshold.

\section{DISCUSSION}

Substantial progress is now being made in developing and implementing approaches for marine ecosystem-based fishery management (e.g. Link 2010, Belgrano \& Fowler 2011, Christensen \& Maclean 2011). A diverse set of modeling tools is being used to guide management options as shown in these recent compilations. For the Northeast US Continental Shelf, a long tradition of multispecies and ecosystem modeling efforts has been used to explore aspects of the dynamics of the system in response to exploitation. Along a continuum from simple to complex model structures, these include aggregate-species surplus production models (Brown et al. 1976), multispecies production models (Sissenwine et al. 1982, Gamble \& Link 2009), donor-controlled multispecies models (Overholtz \& Tyler 1986), recipient-controlled

Fig. 7. Relationship between maximum sustainable yield (MSY) and biomass at MSY ( $\left.B_{\mathrm{MSY}}\right)$ estimates based on Groundfish Assessment Review Meeting (GARM) and hake assessment results (NEFSC 2008) and single-species production model results. The 1:1 line is indicated, and $(\mathbf{\Delta})$ represents the summed estimates for each modeling approach. The insets at the lower right of each panel show only the individual species results and not the total. Statistical comparisons (Spearman rank-order correlations) were done only on the individual species results 

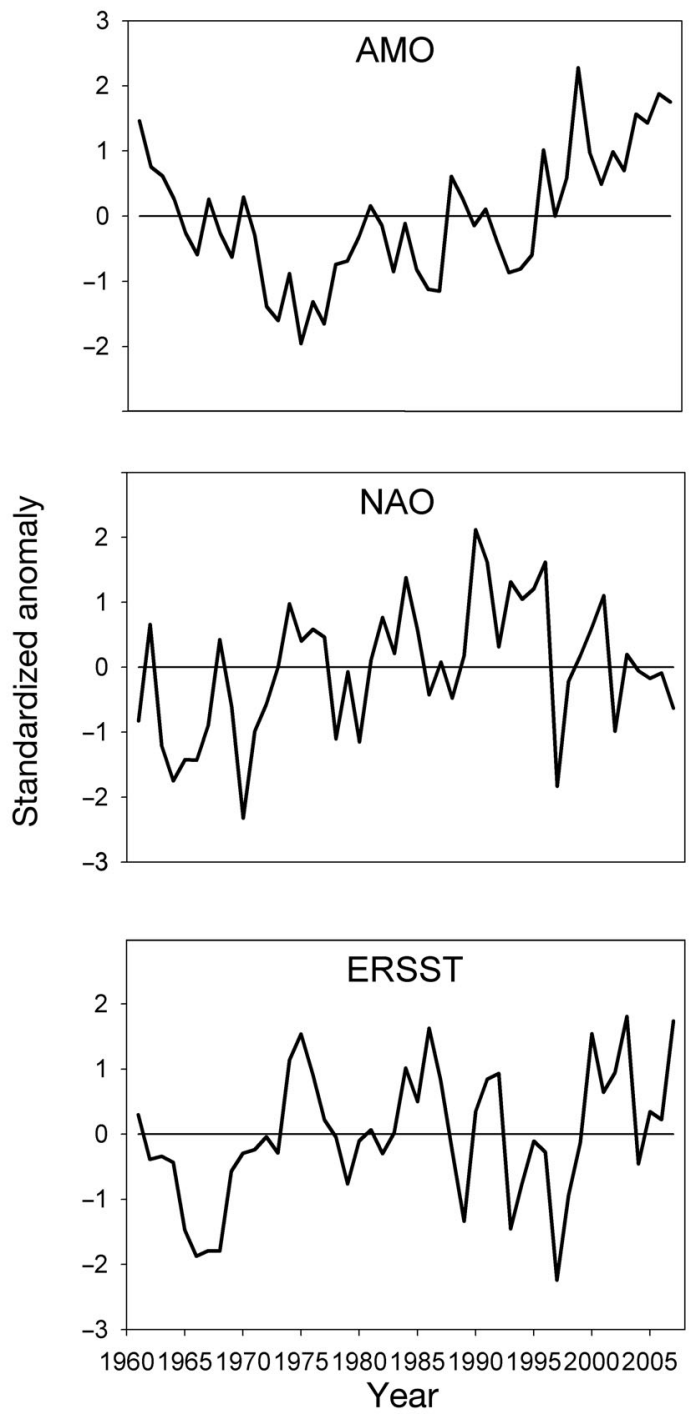

Fig. 8. Environmental and climate-related time series considered in development of the extended production model approach. All variables are expressed as standard normal deviates for the time series represented. AMO: Atlantic multidecadal oscillation. NAO: North Atlantic oscillation. ERSST: Extended reconstructed sea surface temperature

box models (Overholtz \& Link 2009), multispecies delay-difference models (Fogarty et al. 1991, Collie \& DeLong 1999), energy budget and network models (Cohen et al. 1982, Sissenwine et al. 1984, Steele et al. 2007, Link et al. 2008a,b), full age- or size-structured consumption models (Overholtz et al. 1991, 1999), and a coupled physical-ecological-fishery model (ATLANTIS; Link et al. 2011). For a full overview of ecological models developed for this system, see Link et al. (2012). The broad array of modeling approaches applied can be effective in testing for consistency in inferences concerning system dynam-
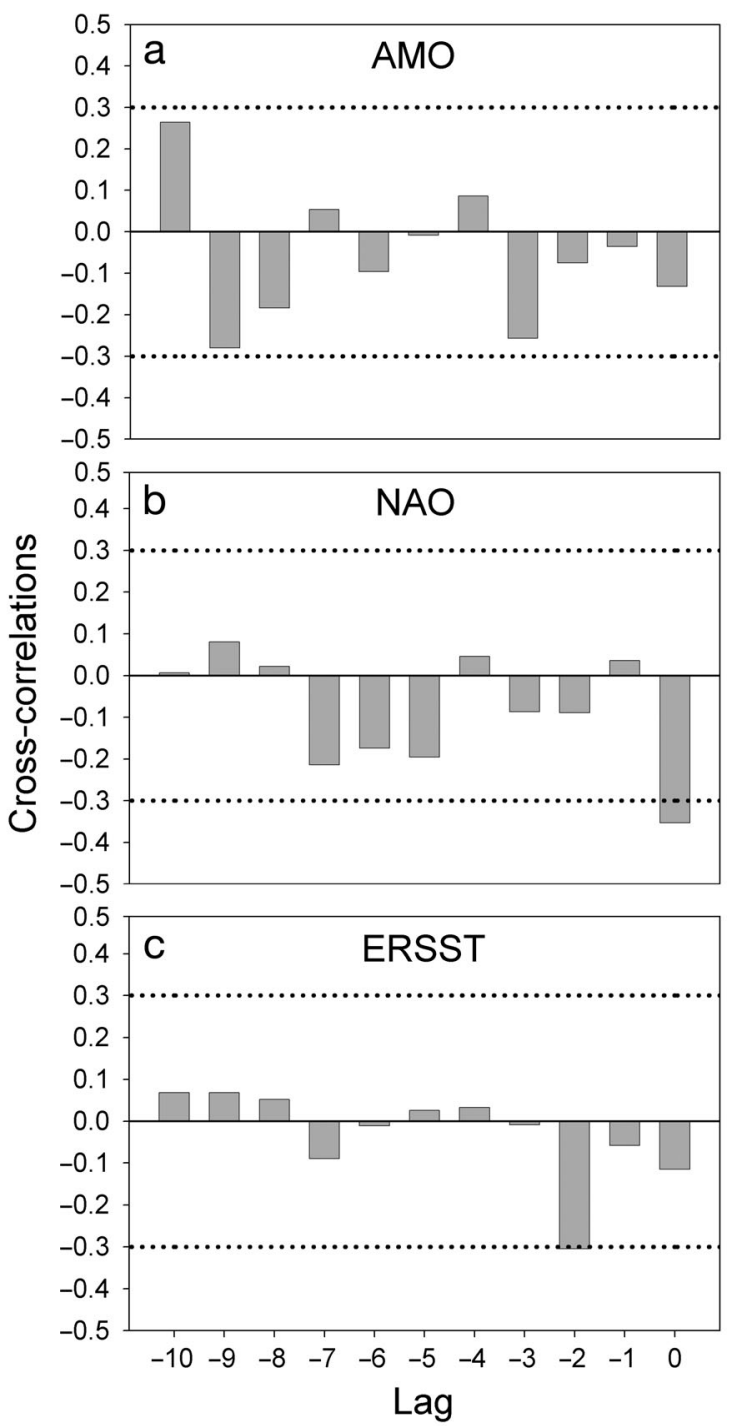

Fig. 9. Cross-correlations between aggregate annual surplus production and (a) the Atlantic Multidecadal Oscillation (AMO), (b) North Atlantic Oscillation (NAO), and (c) Extended Reconstructed Sea Surface Temperature (ERSST). Dashed lines show upper and lower 95\% confidence intervals

ics and the likely utility of alternative management strategies.

Aggregate surplus production models were used as part of an overall management strategy for the Northeast US Continental Shelf by the International Commission for Northwest Atlantic Fisheries nearly $40 \mathrm{yr}$ ago, representing one of the earliest formal applications of an ecosystem approach to fisheries management. Our updated application of simple multispecies models based on aggregate catch and biomass points to the need for conservative ecological reference points that reduce the risk of over-exploitation at the 
Table 3. Change in corrected Akaike Information Criterion $\left(\mathrm{AIC}_{\mathrm{c}}\right)$ scores for extended production models including environmental covariates relative to the base case model of no covariates. NAO: North Atlantic Oscillation, ERSST: Extended Reconstructed Sea Surface Temperature

\begin{tabular}{|lcc|}
\hline Covariates included & Total no. parameters & $\Delta \mathrm{AIC}_{\mathrm{c}}$ \\
\hline $\mathrm{NAO}_{0}, \mathrm{ERSST}_{2}$ & 5 & -1.01 \\
$\mathrm{NAO}_{0}$ & 4 & 1.01 \\
$\mathrm{ERSST}_{2}$ & 4 & 0.004 \\
\hline
\end{tabular}

system level. Our comparison of aggregate surplus production models and single-species analyses indicate that both the aggregate MSY and $B_{\mathrm{MSY}}$ levels are lower for the simple multispecies model, a conclusion consistent with previous analyses. The single-species MSY and $B_{\mathrm{MSY}}$ reference point are $\sim 30 \%$ higher than the aggregate model findings, suggesting that the former may result in more risk-prone decisions. Brown et al. (1976) found differences of a similar magnitude in their early development of an aggregate production model (see also Mayo et al. 1992 and Mueter \& Megrey 2006). Walters et al. (2005) reported differences in management measures derived from single-species and multispecies or ecosystem models that can lead to higher risk when ecological interactions are ignored. Recently, Steele et al. (2011) contrasted single-species results and 2 ecosystem models for Georges Bank species and indicated that all species cannot be simultaneously at high production levels. Not accounting for biological interactions or environmental variability may result in overly optimistic predictions of long-term sustainable yield and unrealistically high estimates of $B_{\mathrm{MSY}}$. An aggregate approach can mitigate such concerns.

The demersal fish assemblage considered here comprises species that are caught together as members of a distinct operational fishery (Lucey \& Fogarty in press), are part of recognized ecological assemblages defined in space and time (Garrison 2001), and are connected through trophic interactions (Smith \& Link 2010). Linkages through predation are particularly strong among the hakes and several of the gadid species (notably cod, pollock, and white hake). In several cases, reciprocal predation patterns are evident among these species. Other components of the assemblage are connected as members of trophic guilds defined on the basis of diet composition. For example, the gadoids mentioned above along with monkfish are part of a piscivore guild while several of the flatfish species are members of a defined benthivore guild (Garrison \& Link 2000).
These interconnections reinforce the importance of considering the assemblage as part of a dynamic system subject to technical and biological interactions. That such a system has different properties than those of the individual species comprising it is not unexpected.

Simulation testing of the performance of full multispecies models (Worm et al. 2009) and aggregate production models (Gaichas et al. 2012) clearly indicate that the vulnerability of weak-link stocks must be carefully considered prior to the application of any aggregate reference points. It is possible to devise precautionary harvesting policies that result in minimum loss in yield using conservative exploitation rates to protect vulnerable species (Worm et al. 2009, Gaichas et al. 2012). Gear modifications or the use of protected areas may also be necessary to safeguard highly vulnerable species.

Estimation of biological reference points for aggregate species assemblages can be used to set upper constraints or caps on removals from the system. It has long been recognized that due to biological or technological interactions, an aggregate quota may be more appropriate for managing species assemblages (May 1975, Pope 1975, 1979, Brown et al. 1976, Fukuda 1976, Mayo et al. 1992, Witherell et al. 2000). If fishing effort is relatively high, incidental catches are important, and species overlap, then consideration of total yield from the complex of available species is appropriate (Garrod 1973). This approach will still require specifying individual target exploitation patterns for the species comprising the assemblage, both to protect vulnerable species as noted above and to prevent targeted overfishing of the more valuable species. In the context of the singlespecies and aggregate-species models considered here, this can be readily accomplished by apportioning the aggregate-level MSY levels to the species level by proportionally adjusting the singlespecies targets downward. Under this approach, the sum of the adjusted individual species targets would be constrained not to exceed the aggregate level. Other approaches can of course be considered for allocating the total catch among species. Solutions that maximize yield or profit from the assemblage subject to constraints that prevent the assemblage total from being exceeded, while also preventing unacceptable declines in individual species, can be constructed and may be preferable.

We note that while we have focused on selected teleost species in this analysis to allow a general comparison with existing groundfish assessments, these species also interact directly with other parts of 
the system, notably with small elasmobranches (dogfish and skates), pelagic fishes, and invertebrates (particularly crustaceans and mollusks) through trophic and, in some cases, technical interactions. The development of a full ecosystem-based fishery management strategy for the GOM will require consideration of this broader set of interactions. Such an approach can be developed as a direct extension of the methods employed here or by considering models that can address interactions among different subgroups (e.g. Fogarty \& Brodziak 1994, Collie \& DeLong 1999) in a multispecies analysis with intermediate levels of aggregation.

Although our analysis of a particular set of environmental or climate-related effects does not warrant inclusion in extended production models at this time, it is clear that we should view overall production in the system as a dynamic process that should be carefully monitored and periodically re-evaluated. There is ample evidence of large-scale changes in physical forcing in this system (Ecosystem Assessment Program 2009), and these changes are manifest in shifts in distribution patterns of marine organisms (Nye et al. 2009, Lucey \& Nye 2010). If overall declines in productivity become evident, the multispecies reference points would have to be adjusted accordingly to reduce the risk of overfishing. This would allow fish stocks to maintain some potential for responding to further environmental change (Hilborn et al. 2003, Stram \& Evans 2009).

Perceived constraints on the application of multispecies and ecosystem models to support ecosystembased fishery management continue to be expressed (e.g. Hilborn 2011). These concerns are largely centered on the data requirements for complex ecological models. While many multispecies and ecosystem models do in fact require information on diet composition, feeding interactions, and other factors that can be difficult and expensive to obtain, our results show the potential utility of quite simple multispecies models in which the interaction terms are implicit rather than explicit. In principle, these methods could provide an avenue for estimation of ecological/multispecies reference points in data-limited situations. They can hold advantages even in data-rich situations where greater stability and predictability of aggregate system dynamics are found. For example, despite significant compositional changes, systemlevel properties including catch, total biomass, and aggregate size composition in the NES LME have been much more stable than the individual components (Hennemuth 1979, Murawski \& Idoine 1992, Fogarty \& Murawski 1998, Auster \& Link 2009).
These characteristics appear to reflect compensatory processes related to a sequence of species replacements under the constraint of overall energy limitations in the system. These characteristics contribute to the greater overall stability and predictability at the system level. Renewed evaluation and potential broader application of simple aggregate production models appear to be warranted to meet the challenge of coping with complexity in ecosystem-based management.

Acknowledgements. We thank L. Col and Sean Lucey for assistance with graphics. We are most appreciative of the many thoughtful comments provided by E. Brooks and L. Jacobson and 4 anonymous referees on an earlier version of this paper. R. Gamble and H. Liu provided analytical assistance.

\section{LITERATURE CITED}

Akaike H (1992) Information theory and an extension of the maximum likelihood principle. In: Kotz S, Johnson $\mathrm{N}$ (eds) Breakthroughs in statistics. Springer Verlag, New York, NY, p 599-609

Apollonio S (2002) Hierarchical perspectives on marine complexities: searching for systems in the Gulf of Maine. Columbia University Press, New York, NY

Auster PJ, Link JS (2009) Compensation and recovery of feeding guilds in a northwest Atlantic shelf fish community. Mar Ecol Prog Ser 382:163-172

Belgrano A, Fowler CW (2011) Ecosystem-based management for marine fisheries: an evolving perspective. Cambridge University Press, Cambridge

Bolster WJ (2008) Putting the oceans in Atlantic history: maritime communities and marine ecology in the Northwest Atlantic, 1500-1800. Am Hist Rev 113:19-47

Box GEP, Jenkins G (1976) Time series analysis: forecasting and control. Holden-Day, Oakland

Brodziak JK, Legault CM, Col LA, Overholtz WJ (2004) Estimation of demersal and pelagic species biomasses in the northeast USA continental shelf ecosystem. ICES CM 2004/FF:07. International Council for the Exploration of the Sea, Copenhagen

Brown BE, Brennan JA, Grosslein MD, Heyerdahl EG, Hennemuth RC (1976) The effect of fishing on the marine finfish biomass in the Northwest Atlantic from the Gulf of Maine to Cape Hatteras. ICNAF Res Bull 12:49-68

Burnham KP, Anderson DR (1998) Model selection and inference: a practical information theoretic approach. Springer, New York, NY

Christensen V, Maclean J (2011) Ecosystem approaches to fisheries: a global perspective. Cambridge University Press, Cambridge

Cohen EB, Grosslein MD, Sissenwine MP, Steimle F, Wright WR (1982) Energy budget for Georges Bank. Publ Spec Can Sci Halieut Aquat 59:95-107

Collie JS, DeLong AK (1999) Multispecies interactions in the Georges Bank fish community. Ecosystem approaches for fisheries management. Report No. 99-01. University of Alaska Sea Grant College Program, Fairbanks, AK

Ecosystem Assessment Program (2009) Ecosystem status 
report for the Northeast U.S. Continental Shelf Large Marine Ecosystem. Ref Doc 99-11. Northeast Fisheries Science Center, Woods Hole, MA

Efron B, Tibshirani RJ (1994) An introduction to the bootstrap. Chapman and Hall/CRC, Boca Raton, FL

Enfield DB, Mestas-Nunez AM, Trimble PJ (2001) The Atlantic multidecadal oscillation and its relation to rainfall and river flows in the continental US. Geophys Res Lett 28:2077-2080

Fogarty MJ, Brodziak JT (1994) Multivariate time series analysis of fish community dynamics on Georges Bank. ICES C.M. 1994/P:3. International Council for the Exploration of the Sea, Copenhagen

Fogarty MJ, Murawski SA (1998) Large-scale disturbance and the structure of marine systems: fishery impacts on Georges Bank. Ecol Appl 8:6-22

Fogarty MJ, Cohen EB, Michaels WL, Morse WW (1991) Predation and the regulation of sand lance populations: an exploratory analysis. ICES Mar Sci Symp 193: $120-124$

Fukuda Y (1976) A note on yield allocation in multistock fisheries. ICNAF Res Bull 12:83-87

Gaichas S, Gamble R, Fogarty M, Benoit H and others (2012) Assembly rules for aggregate-species production models: simulations in support of management strategy evaluation. Mar Ecol Prog Ser 459:275-292

> Gamble RJ, Link JS (2009) Analyzing the tradeoffs among ecological and fishing effects on an example fish community: a multispecies (fisheries) production model. Ecol Model 220:2570-2582

Garrison LP (2001) Spatial patterns of species composition fish community during 1966 to 1999. In: 17th Lowell Wakefield Fish Symp. University of Alaska Sea Grant College Program, Anchorage, AK, p 513-537

Garrison LP, Link JS (2000) Dietary guild structure of the fish community in the Northeast United States continental shelf ecosystem. Mar Ecol Prog Ser 202:231-240

Garrod DJ (1973) Memorandum on the mixed fishery problem in Subarea 5 and Statistical Area 6. ICNAF Res Doc 73/6. International Convention for the Northwest Atlantic Fisheries, Dartmouth, Canada

Hennemuth RC (1979) Man as predator. In: Patil GP, Rosenzweig ML (eds) Contemporary quantitative ecology and related econometrics. p 507-532. International Co-operative Publishing House, Fairland, MD

> Hilborn R (2011) Future directions in ecosystem-based fisheries management: a personal perspective. Fish Res 108: 235-239

Hilborn R, Quinn TP, Schindler DE, Rogers DE (2003) Biocomplexity and fisheries sustainability. Proc Natl Acad Sci USA 100:6564-6568

Hurrell JW (1995) Decadal trends in the North Atlantic Oscillation: regional temperatures and precipitation. Science 269:676-679

> Jacobson LD, Cadrin SX, Weinberg JR (2002) Tools for estimating surplus production and $F_{\mathrm{MSY}}$ in any stock assessment model. N Am J Fish Manag 22:326-338

Lear WH (1998) History of the fisheries of the Northwest Atlantic: the 500-year perspective. J Northwest Atl Fish Sci 23:41-73

Link JS (2010) Ecosystem-based fishery management: confronting tradeoffs. Cambridge University Press, Cambridge

Link JS, Griswold CA, Methratta ET, Gunnard J (eds) (2006) Documentation for the energy modeling and analysis exercise (EMAX). Reference Document 06-15. Northeast Fisheries Science Center, Woods Hole, MA

Link J, O'Reilly J, Fogarty M, Dow D and others (2008a) Energy flow on Georges Bank revisited: the energy modeling and analysis exercise in historical context. J Northwest Atl Fish Sci 39:83-101

Link J, Overholtz W, O'Reilly J, Green J and others (2008b) An overview of EMAX: the Northeast U.S. Continental Shelf Ecological Network. J Mar Syst 74:453-474

Link JS, Gamble R, Fulton E (2011) NEUS - Atlantis: construction, calibration, and application of an ecosystem model with ecological interactions, physiographic conditions, and fleet behavior. Tech Memo TM F/NE-218. NOAA Fisheries Service, Northeast Fisheries Science Center, Woods Hole, MA

Link JS, Gamble R, Fogarty MJ (2012) An overview of the Northeast Fisheries Science Center ecosystem modeling enterprise. Lab Ref Doc. Northeast Fisheries Science Center, Woods Hole, MA

Lucey SM, Fogarty MJ (in press) Spatially explicit operational fisheries in New England. Fish Res

> Lucey SM, Nye J (2010) Shifting species assemblages in the Northeast US Continental Shelf Large Marine Ecosystem. Mar Ecol Prog Ser 415:23-33

May AW (1975) Report of standing committee on research and statistics. ICNAF Seventh Special Commission Meeting - September 1975. International Convention for the Northwest Atlantic Fisheries,

Mayo RK, Fogarty MJ, Serchuk FM (1992) Aggregate fish biomass and yield on Georges Bank, 1960-87. J Northwest Atl Fish Sci 14:59-78

> Mueter FJ, Megrey BA (2006) Using multi-species surplus production models to estimate ecosystem-level maximum sustainable yields. Fish Res 81:189-201

Murawski SA, Idoine JS (1992) Multispecies size composition: a conservative property of exploited fishery systems? J Northwest Atl Fish Sci 14:79-85

NEFSC (Northeast Fisheries Science Center) (2008) Assessment of 19 northeast groundfish stocks through 2007: report of the 3rd Groundfish Assessment Review Meeting (GARM III), Northeast Fisheries Science Center, Woods Hole, Massachusetts, August 4-8, 2008. Ref Doc 08-15. US Department of Commerce, NOAA Fisheries, Northeast Fisheries Science Center, Woods Hole, MA

> Nye JA, Link JS, Hare JA, Overholtz WJ (2009) Changing spatial distribution of fish stocks in relation to climate and population size on the Northeast United States continental shelf. Mar Ecol Prog Ser 393:111-129

Overholtz WJ, Link JS (2009) A simulation model to explore the response of the Gulf of Maine food web to large-scale environmental and ecological changes. Ecol Model 220: 2491-2502

> Overholtz WJ, Tyler AV (1986) An exploratory simulation model of competition and predation in a demersal fish assemblage on Georges Bank. Trans Am Fish Soc 115: 805-817

Overholtz WJ, Murawski SA, Foster KL (1991) Impact of predatory fish, marine mammals, and seabirds on the pelagic fish ecosystem of the northeastern USA. ICES Mar Sci Symp 193:198-208

Overholtz WJ, Link JS, Suslowicz LE (1999) Consumption and harvest of pelagic fishes and squids in the Gulf of MaineGeorges Bank ecosystem. In: Ecosystem Approaches for Fisheries Management. Rep No. 99-01. University of Alaska Sea Grant College Program, Fairbanks, AK, p 163-186 
Pope JG (1975) The application of mixed fisheries theory to the cod and redfish stocks of subarea 2 and division $3 \mathrm{~K}$. ICNAF Res Doc75/IX/126. International Convention for the Northwest Atlantic Fisheries, Dartmouth, Canada

Pope J (1979) Stock assessment in multistock fisheries, with special reference to the trawl fishery in the Gulf of Thailand. SCS/DEV/79/19. FAO, Manila

Quinn TJ, Deriso RB (1999) Quantitative fish dynamics. Oxford University Press, Oxford

Ralston S, Polovina JJ (1982) A multispecies analysis of the commercial deep-sea handline fishery in Hawaii. Fish Bull 80:435-448

Rosenberg AA, Claesson SH (2008) Stellwagen Bank marine historical ecology final report. Gulf of Maine Cod Project. University of New Hampshire, Durham, NH

Sissenwine MP, Brown BE, Palmer JE, Essig RW, Smith W (1982) Empirical examination of population interactions for the fishery resources off the Northeastern USA. Publ Spec Can Sci Halieut Aquat 59:82-94

Sissenwine MP, Cohen EB, Grosslein MD (1984) Structure of the Georges Bank ecosystem. Rapp P-V Reun Int Cons Explor Mer 183:243-254

Smith, BE, Link JS (2010) The trophic dynamics of 50 finfish and 2 squid species on the Northeast U.S. Continental Shelf. Tech Memo NMFS-NE-216. US Department of Commerce, NOAA, NMFS, Northeast Fisheries Science Center, Woods Hole, MA

Smith TM, Reynolds RW (2003) Extended reconstruction of global sea surface temperatures based on COADS data

Submitted: October 31, 2011; Accepted: April 27, 2012
(1854-1997). J Clim 16:1495-1510

> Smith TM, Reynolds RW (2004) Improved extended reconstruction of SST (1854-1997). J Clim 17:2466-2477

Sparholt H, Cook RM (2009) Sustainable exploitation of temperate fish stocks. Biol Lett: doi:10:1098/rabi.2009:0516

Steele J, Bisagni J, Collie J, Fogarty M and others (2007) Constructing end-to-end budgets for the Georges Bank ecosystem. Prog Oceanogr 74:423-448

> Steele JH, Gifford DJ, Collie JS (2011) Comparing species and ecosystem-based estimates of fisheries yield. Fish Res 111:139-144

- Stenseth NC, Mysterud A, Ottersen G, Hurrell JW, Chan KS, Lima M (2002) Ecological effects of climate fluctuations. Science 297:1292-1296

> Stram DL, Evans DCK (2009) Fishery management responses of climate change in the North Pacific. ICES J Mar Sci 66:1633-1639

Sugihara G (rapp) (1984) Ecosystem dynamics. In: May RM (ed) Exploitation of marine communities. Life Sci Res Rep 32. Springer-Verlag, Berlin, p 131-154

Walters CJ, Christensen V, Martell SJ, Kitchell JF (2005) Possible ecosystem impacts of applying MSY policies from single-species assessment. ICES J Mar Sci 62: 558-568

> Witherell D, Paltzke C, Fluharty D (2000) An ecosystem approach for Alaska groundfish fisheries. ICES J Mar Sci 57:771-777

Worm B, Hilborn R, Baum JK, Branch TA and others (2009) Rebuilding global fisheries. Science 325:578-585

Proofs received from author(s): July 2, 2012 